\title{
Arquivo Aguirra. Fonte documental sobre a formação territorial de São Paulo
}

\author{
Walter Pires \\ Depto. do Patrimônio Histórico-Prefeitura de São Paulo
}

O acervo documental conhecido como Arquivo Aguirra - produzido, coletado e organizado por João Baptista de Campos Aguirra (1871-1962) é constituído por uma coleção de fichas, mapas, cadastros, livros, fotografias, entre outros itens, que integram um dos fundos do Serviço de Documentação Textual e Iconográfica do Museu Paulista da Universidade de São Paulo.

Trata-se de uma coleção relevante para pesquisadores que buscam dados sistemáticos sobre a história paulista, principalmente quanto à organização e divisão fundiária do território de São Paulo. Há um conjunto expressivo de dados referentes a propriedades rurais ou urbanas que incluem identificação e dados biográficos sobre proprietários, registros de sesmarias, registros paroquiais de terras e cartografia associada a esses temas.

Incorporado ao Museu Paulista em 1962, tem se revelado desde então - quando passou à condição de acervo público - uma fonte promissora de dados para pesquisas relacionadas à formação histórica e geográfica de São Paulo.

Algumas características desse acervo, porém, dificultam uma pesquisa mais rápida e certamente mais produtiva desse material, como: a grande quantidade e diversidade de informações, sem uma aparente articulação temática; o longo período cronológico coberto por esses documentos; o fato da organização do material pesquisado obedecer a critérios que se ajustavam à personalidade e interesses de seu organizador; e a dificuldade de leitura de muitas das fichas, em sua maioria manuscritas e com anotações resumidas.

A pesquisa que realizamos em parte desse acervo, para a elaboração de nossa dissertação de Mestrado', permitiu compreender melhor o conteúdo da documentação sobre terras do Arquivo Aguirra, bem como sua importância para uma visão de conjunto, principalmente dos negócios
1. Configuração territorial, urbanização $e$ patrimônio: Colônia da Glória (1876-1904). Dissertação apresentada à Faculdade de Arquitetura e Urbanismo da Universidade de São Paulo para a obtenção de título de Mestre em Arquitetura e Urbanismo.Aprovada em 2003 sob a orientação da Profa. Dra. Ana Lúcia Duarte Lanna. 
2. O nome de família é Aguirre, no entanto ele mesmo passou a assinar Aguirra, como consta nos artigos, cartas e outros documentos de seu acervo.

3. No acervo do Museu Paulista há uma significativa coleção de fotografias de familiares e amigos de Aguirra, muitas datadas do final do século XIX, nos formatos correntes (carte de visite, carte cabinet) $\mathrm{e}$ produzidas por fotógrafos atuantes em São Paulo e outras cidades nesse período (Nickelsen, Iglesias e Bredit,Henschel e Benque, Renouleau,Augusto Pinto, Sainatti, Pompe) imobiliários efetivados em nossa área de estudo: o antigo Núcleo Colonial da Glória, que corresponde aos atuais bairros do Cambuci, Vila Deodoro, Glória e parte de Vila Mariana, na cidade de São Paulo.

Aguirra - biografia mínima

João Baptista de Campos Aguirra nasceu na cidade de Limeira (SP), em 4/9/1871, filho de João Baptista de Campos Pinto e de Rosa Amélia de Aguirre $^{2}$. Sobre sua juventude e formação foram localizados poucos dados nas pesquisas realizadas até o presente, tanto nos documentos que se encontram no Museu Paulista ${ }^{3}$, como junto ao Instituto Histórico e Geográfico de São Paulo (IHGSP), do qual foi sócio.

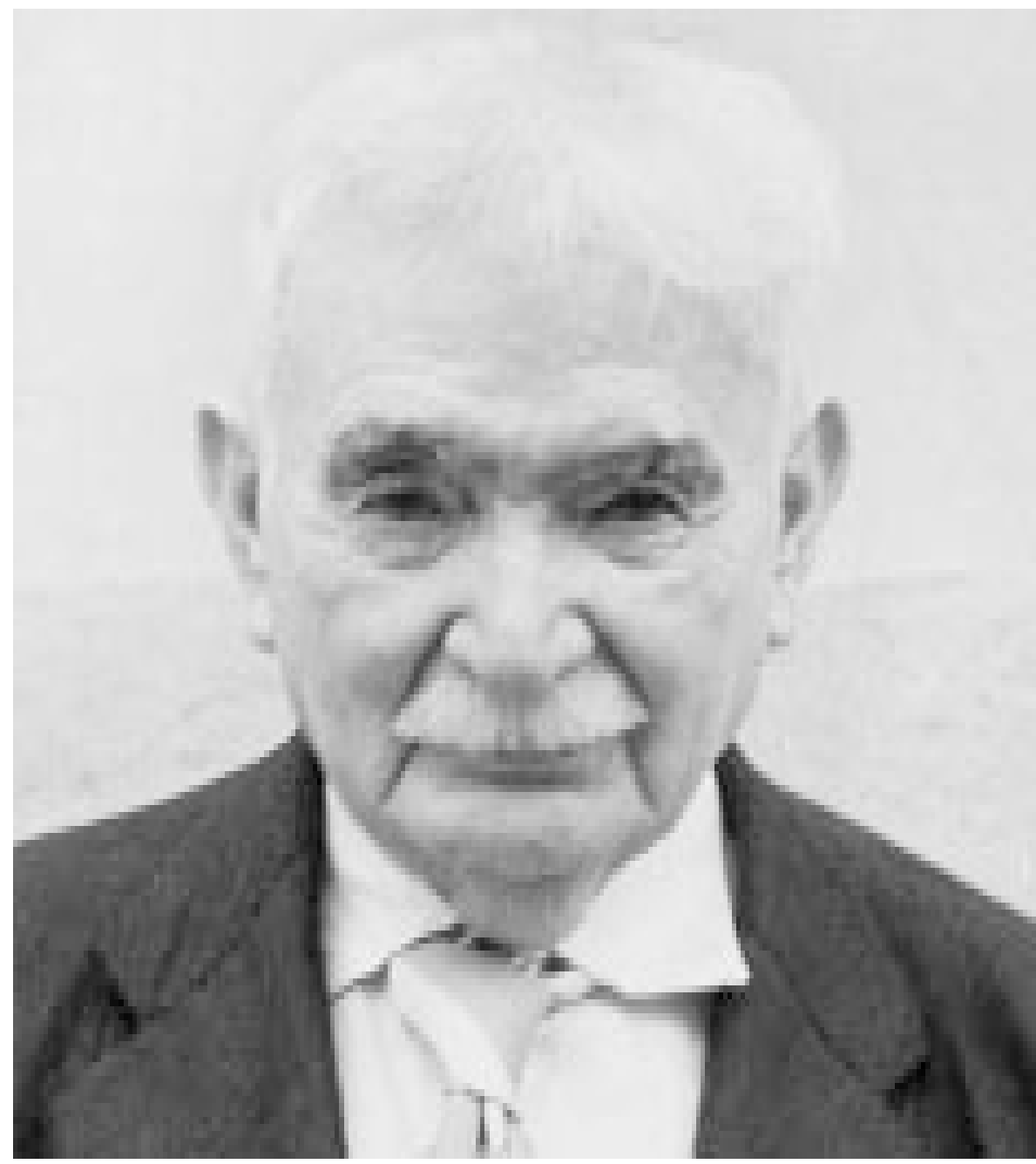

FIGURA 1 - João Baptista de Campos Aguirra (Limeira/SP, 1871 - Bragança Paulista/SP, 1962). Acervo Museu Paulista da USP. Reprodução de Hélio Nobre. 
Nas décadas de 1920 e 1930, no entanto, localizam-se referências sobre a firma Aguirra \& Cia - Comissários, de sua propriedade, cujo endereço era a Rua da Quitanda, n. 17, no centro de São Paulo. Essa empresa foi proprietária de terras, sendo que alguns desses imóveis localizavam-se na zona sul da capital${ }^{4}$.

Em seu acervo há documentos da década de 1940 relativos a outra empresa, situada na Rua Libero Badaró, n. 452, 3-andar ${ }^{5}$, cuja denominação Informação Aguirre. Informações sobre títulos de propriedades imobiliárias corresponde à atividade comercial e arquivística que passou a ser conhecida também como Arquivo Aguirra. Além de local de trabalho, Aguirra ali residiu por cerca de duas décadas, até poucos anos antes de sua morte ocorrida em Bragança Paulista (SP), em 12/10/1962, onde fora morar com familiares ${ }^{6}$.

Sócio do Instituto Histórico e Geográfico de São Paulo (IHGSP) e do Centro de Ciências e Letras de Sorocaba (SP), a ficha que propõe seu nome para o IHGSP, onde é admitido em 1924, informa que se trata de "(...) commissario no alto commercio de São Paulo, grande conhecedor e pesquisador da História Paulista"7 .

Nas revistas do IHGSP, além dos artigos preparados por Aguirra, há registros de algumas das atividades que exerceu, como a organização do arquivo e biblioteca daquela entidade no início da década de 1930; sua participação, em 1926, na comissão sobre a questão de limites entre os Estados de São Paulo e Minas Gerais, presidida por Afonso Antonio de Freitas ${ }^{8}$; sua presença em algumas das diretorias do Instituto como tesoureiro ou membro de comissões, até a década de 1950.

$\bigcirc$ Dicionário de Autores Paulistas, de Luís Correia de Melo, editado em 1954, identifica-o como historiador, certamente pela prática, interesse e produção intelectual, não pela formação. Traz, também, uma lista de referências bibliográficas de sua autoria, com destaque para artigos publicados nas revistas do $\mathbb{H G S P}$ e do Arquivo Histórico Municipal, da Prefeitura de São Paulo. Os temas predominantes nesses artigos revelam o foco de seu interesse como pesquisador e como profissional: a questão de terras e seus proprietários, especialmente em São Paulo.

Entre 1934 e 1935, Aguirra publicou sete artigos na Revista do Arquivo Histórico Municipal de São Paulo, cujos temas eram questões orçamentárias, estatísticas e de propriedades dos séculos XVIII e XIX. Não voltou a publicar nessa revista, que manteve periodicidade regular durante os anos 1940 e 1950.

Na Revista do IHGSP publicou, no período de 1928 a 1938, cinco extensos trabalhos de compilação de dados sobre sesmarias, provisões e patentes, cuja origem está no fichário e na organização de informações cartoriais que produziu como atividade profissional, e que integram o acervo que hoje pertence ao Museu Paulista (FIGURAS 3-6).

Esses artigos, em sua maioria, reproduzem os trabalhos de organização de dados realizados por Aguirra ou documentos por ele coletados, que integravam seu arquivo". Numa "nota necessária" a um dos artigos da Revista do IHGSPIO, comenta um dos problemas recorrentes sobre a questão de propriedades - a falsificação de dados - quando informa que "depois de ter fichado diversos livros do Archivo do Estado, em 1926, foram nelles criminosamente lançados varios registros parochiaes e cartas de sesmarias". Esse dado revela também o alcance de seu trabalho, que permitiu identificar tais falsificações.

Em entrevista ao jornal Diário da Noite, publicada em 18/1/1941, Aguirra informava que realizava "permutas" com cartórios: estes forneciam cópias de documentos em troca de um fichário completo, organizado. Afirmava que seu acervo era resultado de mais de vinte anos de pesquisa e deveria conter cerca de 500 mil fichas.
4. Uma das glebas que deram origem ao loteamento do bairro do Jardim da Saúde, por exemplo, pertenceu a essa empresa.

5. O Edifício Meira Botelho na Rua Líbero Badaró, onde Aguirra ocupou o conjunto 36 por um longo período, ainda existe e constitui-se num prédio eclético, originalmente residencial com uso comercial no térreo. O edifício foi adquirido por Joaquim Meira Botelho, comerciante de café, que o alugava e de quem Aguirra era amigo; posteriormente os apartamentos foram adaptados para escritórios. Informações prestadas por Joaquim Pires de Campos, neto de Botelho, em outubro de 2003.

6. Informações familiares obtidas em novembro de 2003 com Antonio Ferreira de Aguirre e José Eduardo Suppioni de Aguirre, sobrinho e sobrinho-neto de Aguirra.

7. Livro de registros de sócios.Acervo IHGSP.

8. Afonso Antônio de Freitas (1870-1930) teria sido amigo de Aguirra e é quem encabeça sua ficha de admissão ao instituto, do qual foi presidente. No acervo do Museu acha-se arquivado um recorte do jornal A Gazeta, de 3/1/1935, no qual há uma fotografia em que ambos acompanham Armando de Arruda Pereira numa visita à casa da antiga Fazenda Morumby (Localização: SDTI - A1Pr7P6). 


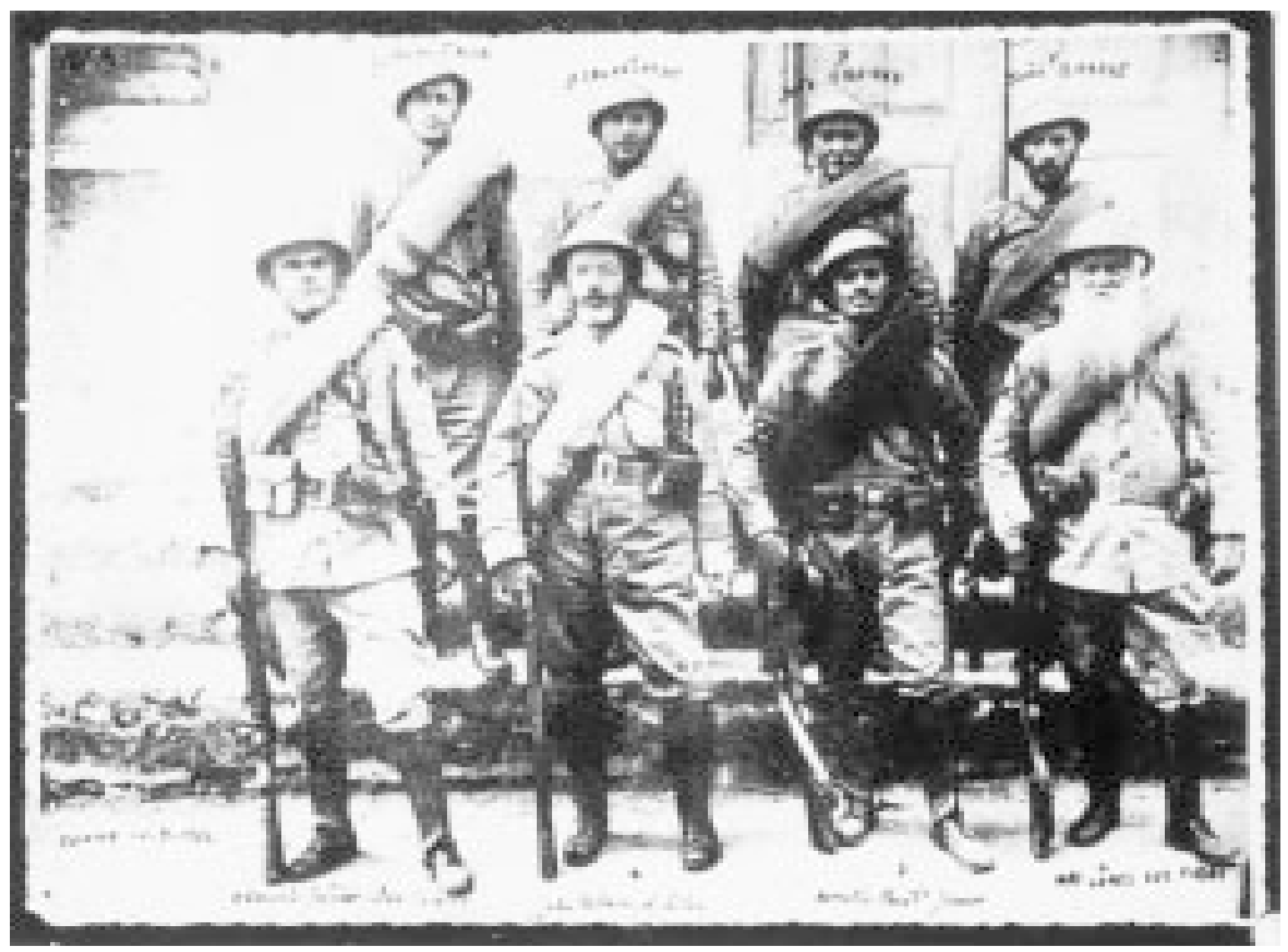

FIGURA 2 - Soldado Aguirra (ao fundo, o terceiro da esquerda para a direita). Cunha/SP, 10/7/1932. Acervo Museu Paulista da USP. Reprodução de Hélio Nobre.

Nessa entrevista destacava ainda alguns conflitos de propriedades que ocorreram em São Paulo, envolvendo demandas judiciais em grandes áreas de terras, como: Vila Mariana, na área do córrego da Traição com o córrego do Sapateiro; Ibirapuera, na área conhecida como Chácara Moreira; em terrenos nas margens do rio Tietê; e na concessão de terras no Tatuapé, a partir das quais um banco julgou-se com direitos até o lbirapuera ${ }^{11}$.

Aquisição do acervo pelo Museu Paulista

As negociações oficiais para a aquisição pelo Museu Paulista, então subordinado à Secretaria da Educação do Estado de São Paulo, do acervo de documentos pertencentes a João Baptista de Campos Aguirra, iniciaram-se em 
agosto de 1960, por iniciativa de Mário Neme (1918-1973), jornalista, escritor e historiador, que era o diretor-substituto do Museu naquele momento ${ }^{12}$

Nesse ofício Mário Neme informa que surgira a "possibilidade de adquirir a mais valiosa coleção de documentos relativos a São Paulo já reunida por um particular, o chamado 'Arquivo Aguirra' ". Acrescenta que:

Já desde alguns meses vimos mantendo contacto com o sr. João Baptista Aguirra e membros de sua família (por se encontrar êle recolhido ao leito), a fim de convencê-lo a vender ao Museu Paulista a sua coleção. Depois de insistir por algum tempo em pedir um preço excessivo, acabou ele concordando com a oferta de um milhão de cruzeiros, por estar convencido de que, com a sua morte, a coleção se dispersará irremediavelmente, sabido que é, por quantos se dedicam à história de São Paulo, que há muitos interessados, pessoas e entidades, em determinados documentos ou maços de documentos da coleção.

Em março de 1960, a Seção de História do Museu realizou exame no acervo, verificando que se mantinha intacto e que era composto por livros e coleções de revistas; conjunto de cartas geográficas; volumes sobre movimento de imóveis com índices onomásticos, geográficos e cronológicos; e fichário da matéria correspondente às questões de registros e vendas de terras. Esse relatório, além de destacar a importância da coleção, considera que

[...] se se tratasse, agora, de recolher os mesmos dados, na amplitude em que ali se apresentam, supondo-se intactas todas as fontes, seria isso tarefa nada menos que para uma equipe de pesquisadores dedicada ao trabalho varios anos. ${ }^{13}$

Em carta ao diretor do Museu, assinada pelo próprio Aguirra, não datada, este informa que "há mais de quarenta anos que me dedico em arquivar documentos não só de São Paulo como de algumas de suas principais cidades [... possuo um cabedal de autênticos documentos, uma sintêse dos Cartorios da Capital". Apesar de ter recebido propostas de empresas e bancos, seu desejo é que o Estado de São Paulo "tenha sob sua guarda êsses documentos, que poderão enriquecer o patrimonio literario e cultural do Estado"14.

A proposta de aquisição foi analisada pela administração do Estado e, em março de 1962, o subchefe do Gabinete da Secretaria da Educação, Oscar Klabin Segall, emitiu parecer favorável à pretensão do Museu, considerando se tratar:

[...] de um Arquivo de grande valor, não só do ponto de vista prático e comercial, como também histórico. Frequentemente é essa valiosa coleção de documentos relativos a São Paulo consultada por engenheiros, peritos e advogados do Estado, da Municipalidade e particulares, que aí vão buscar em documentos procedentes de registros paroquiais, tombamentos oficiais, da época colonial, e dos quais só existe uma via, informações sôbre questões de terra, contratos particulares e processos, o que justifica e põe em relêvo o seu valor prático e comercial. ${ }^{15}$

Finalmente, em 17/4/1962, o governador do Estado, Carlos Alberto A. de Carvalho Pinto, autorizou a compra do acervo, cujo pagamento se efetivou em junho de 1962. ${ }^{16}$

Aguirra faleceu em outubro de 1962, um mês após completar 91 anos, e poucos meses após a aquisição de seu Arquivo pelo Museu Paulista.

Em 1977, em artigo para os Anais do Museu Paulista, Maria Cecília Stávale Malheiro registrou que essa aquisição contou também com a colaboração de Hélio Damante (1919-2002), político, jornalista e escritor, à época assistente
9. Na edição de junho de 1939 da Revista do IHGSP (vol. XXXVI) foram publicados cinco documentos com o título Arquivo Aguirra. Documentos Interessantes. A redação da revista, em nota de agradecimento a Aguirra, dá a entender que ocorreriam outras publicações de seu acervo, o que não se efetivou.

10. Revista do IHGSP, vol. XXVIII, 1930, p. 581 e 582.

11. Deve referir-se, provavelmente, à conhecida e longa disputa judicial sobre a posse e domínio de terras ao longo do rio Tietê, envolvendo concessões transferidas ao Banco Evolucionista, em 1891.

12. Ofício n. 255 , de $17 / 8$ / 1960 , encaminhado ao secretário da Educação,prof. Luciano Vasconcelos de Carvalho,f.2, processo SE$66.762 / 1960$. As informações relativas a essa aquisição foram obtidas nos processos SE-66.762/1960 e SE-86.101/1961, da Secretaria de Estado dos Negócios da Educação.

13. Relatório de Francisco Rodrigues Leite, chefe da Seção de História do Museu Paulista,f. 4 , processo SE-66.762/1960.

14. F. 4-A, processo SE$66.762 / 1960$ 
15. F. 16 , processo SE$86.101 / 1961$.

16. Fs. 18 e 24 , processo SE-86.101/1961. particular do governador Carvalho Pinto (MALHEIRO, 1977/78; MENEZES, 1978). Acrescentou que:

[...] o arquivo foi organizado para fins outros que não os históricos ou geográficos: o Sr. Aguirra era um profundo conhecedor de questões de propriedade imobiliária na Capital e no Estado de São Paulo e o arquivo era uma fonte de renda para ele, porque atendia a consultas de advogados e demais interessados [...] (MALHEIRO, op.cit., p. 201).

Esse artigo se constitui numa adequada apresentação ao acervo e estabelece um quadro geral dos documentos contidos nesse fundo arquivístico, dividido em seis grandes áreas, que correspondem à tipologia dos documentos, além da biblioteca com obras de referência. As séries documentais descritas são as seguintes (MALHEIRO, op.cit., p. 202-205):

1. Acervo cartográfico (cerca de 1.500 mapas e plantas).

2. Fichário com transcrições, em geral manuscritas, de dados de registros paroquiais, cartas de sesmarias, inventários, escrituras, artigos de jornal, etc. Subdividido em seis séries temáticas de fichas.

3. Livros com índices de dados recuperados de cartórios, censos, tabeliães, autos judiciais, etc.

4. Pastas com documentos sobre divisão de propriedades rurais na capital e no interior do Estado.

5. Autos e plantas de juízes comissários, cópias do Patrimônio Imobiliário do Estado.

๑. Folhetos sobre questões judiciais do Tribunal de Justiça.

Fichário de informações sobre propriedade de terras

Para a pesquisa que realizamos sobre a organização territorial da área da antiga Colônia da Glória, consultamos principalmente os três primeiros conjuntos documentais indicados no artigo de Maria Cecília Malheiro.

O conjunto de dados sobre as características, descrições e sucessões de propriedades de terras do Arquivo Aguirra distribui-se em torno de três conjuntos principais de fichas, que resultaram também em alguns índices sistemáticos desenvolvidos por Aguirra' ${ }^{17}$ : 1. Série Sesmarias; 2. Série Registros Paroquiais; e 3. Série Inventários.

\section{Série Sesmarias}

\section{Características}

Fichas manuscritas, em sua maioria, ou datilografadas $(10 \times 15 \mathrm{~cm})$, contendo traslados ou extratos com descrição de sesmarias, organizadas em ordem alfabética pela freguesia, comarca ou região onde se localiza a propriedade. Inclui as seguintes regiões: Goiás, Mato Grosso, Paraná, Rio Grande do Sul, Santa Catarina, São Paulo / Sorocaba. As fichas não apresentam organização - cronológica, alfabética dentro de cada subdivisão geográfica. 
Carimbo: SESMARIA.

Identificação geral: freguesia, comarca ou região (termo que organiza o fichário). Ex: Apiahy, Araraquara, Paraná, São Paulo/Sorocaba, etc. (pode incluir mais de uma localidade, dependendo dos limites da sesmaria).

Identificação específica: bairro ou área onde se situa a propriedade, podendo corresponder à designação da própria sesmaria. Ex: Apiahy / Taquarussu; Apiahy / Sumidor.

Descrição resumida da propriedade: deve corresponder à transcrição literal dos termos do documento original fichado. Em destaque - grifado, caixa alta - nome da propriedade, de acidentes geográficos importantes, proprietários indeiros.

Data: não está registrada em todas as fichas.

Referência do documento original: Livro de Patentes, Provisões e Sesmarias ou outros (indicação do número do livro e das folhas). Ex:
17. Aguirra organizou índices datilografados das fichas de sesmarias e de registros paroquiais, por ordem alfabética de interessados ou de localidades, que resultaram em livros encadernados que integram o acervo do Museu Paulista. Alguns desses índices correspondem aos que foram publicados na Revista do IHGSP. Ver nota 10.

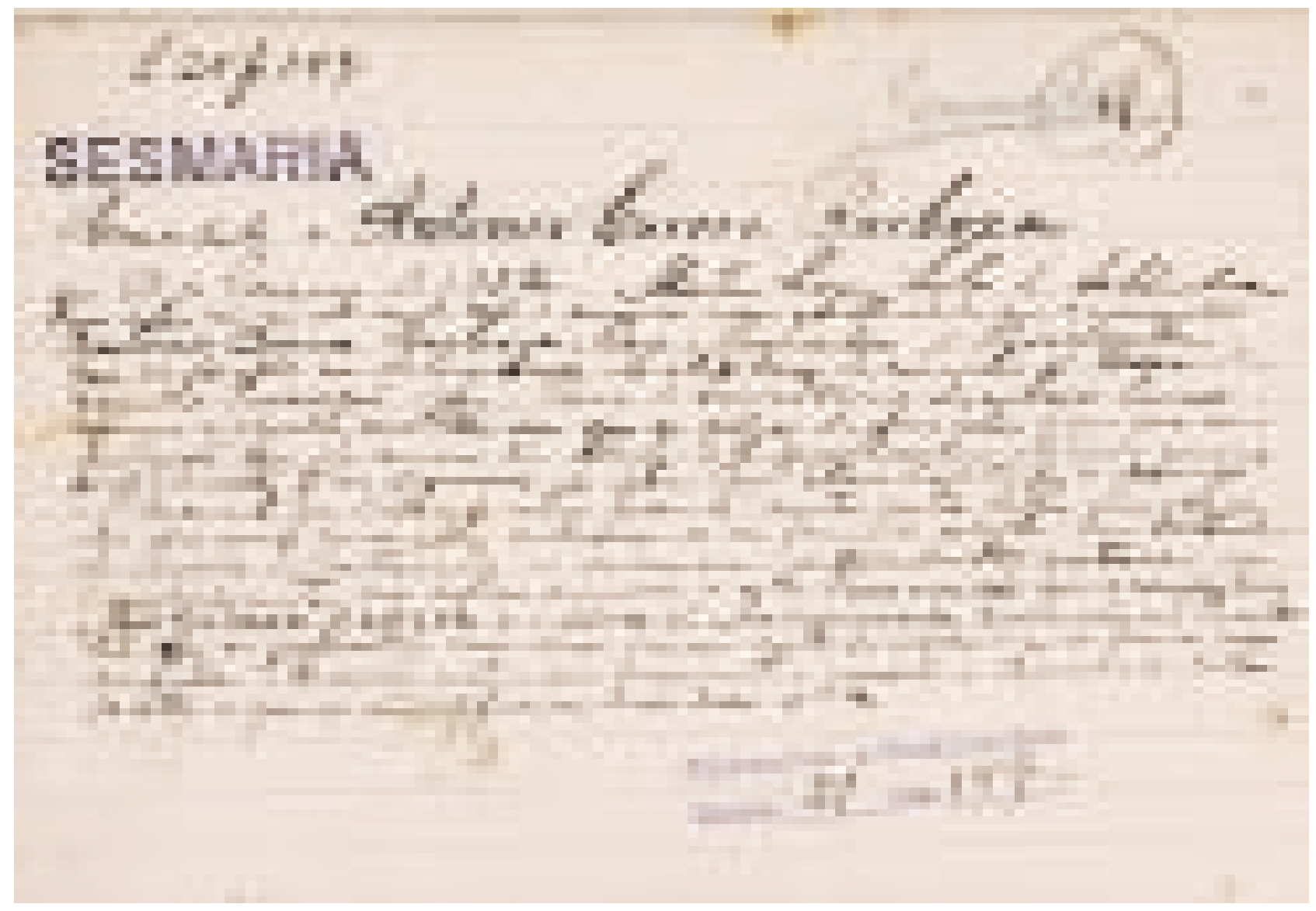

FIGURA 3 - Série Sesmarias. Ficha manuscrita de Aguirra com resumo de concessão de Sesmaria a Antonio Correa Barboza, em Piracicaba no ano de 1782. Acervo Museu Paulista da USP. Reprodução de Hélio Nobre. 
Archivo do Estado - Livro 21, f. 122s; Sesmarias - vol. 4, f. 38 (corresponde ao volume editado pelo Arquivo do Estado).

2. Série Registros Paroquiais

Características

Fichas manuscritas ou datilografadas (10 × $15 \mathrm{~cm})$, contendo dados sobre os Registros de Terras, obrigatórios a partir da Lei de Terras de 1850, realizados pelas paróquias, entre 1855 e 1860, aproximadamente. Organizadas em ordem alfabética de paróquias, freguesias, vilas. Em cada paróquia as fichas podem estar ordenadas ou não, dependendo do local, por ordem numérica de registro.

Conteúdo das fichas

Carimbo: REGISTRO PAROCHIAL.

Identificação geral: paróquia, freguesia, vila - é o termo que organiza o fichário.

Identificação específica: bairro ou lugar.

Número do Registro Paroquial

Identificação do(s) proprietário(s): em letra maior ou em destaque.

Transcrição da declaração de propriedade: com destaque para o nome do local, da propriedade ou de proprietários vizinhos.

Local e data da declaração

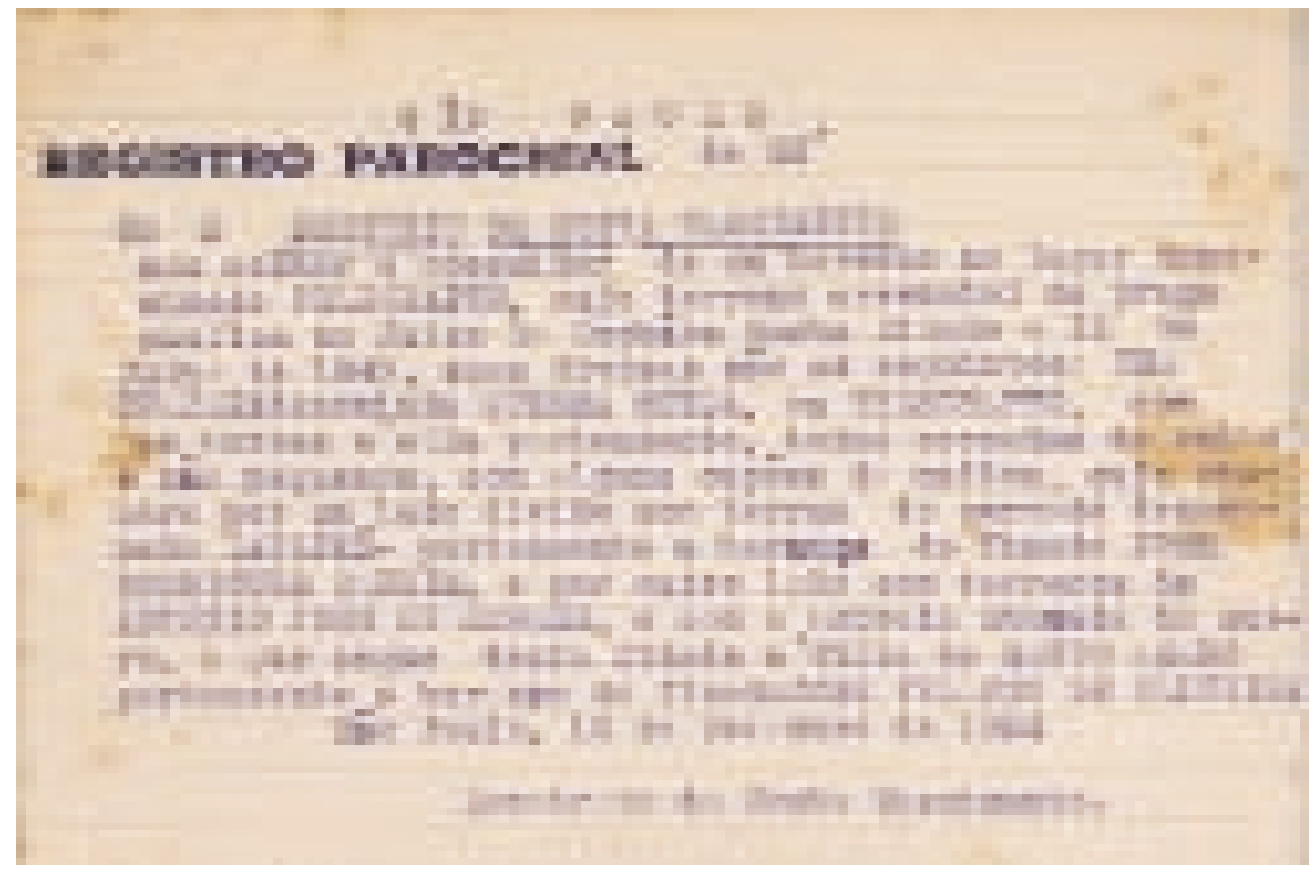

FIGURA 4 - Série Registros Paroquiais. Ficha datilografada de Aguirra com resumo do Registro n. 
Data do registro: pelo vigário; nem sempre consta da ficha esse dado. Declarante: o proprietário ou alguém "a rogo de", Escrivão

3. Série Inventários

Características

Fichas manuscritas ou datilografadas (10 $15 \mathrm{~cm})$, contendo dados sobre outras categorias de negócios ou transferências de propriedades de imóveis, destacando-se: escrituras de compra e venda (com a referência do cartório), escrituras de partilha ou doação, acórdãos, editais de praça, inventários e testamentos. Há fichas com informações variadas sobre dados históricos, geográficos, econômicos, etc. das localidades (cidades, vilas).

As fichas não apresentam organização - cronológica, alfabética dentro de cada subdivisão geográfica.

Conteúdo das fichas

Como se trata de uma série composta de dados variados, não há um padrão comum a todas as fichas. Aquelas relativas às escrituras registradas em cartórios, em grande número, apresentam certos padrões: Identificação geral: cidade, vila.

Identificação específica: bairro ou região - é o termo que organiza o fichário. Descrição: identifica o assunto da escritura (venda, doação, etc.).

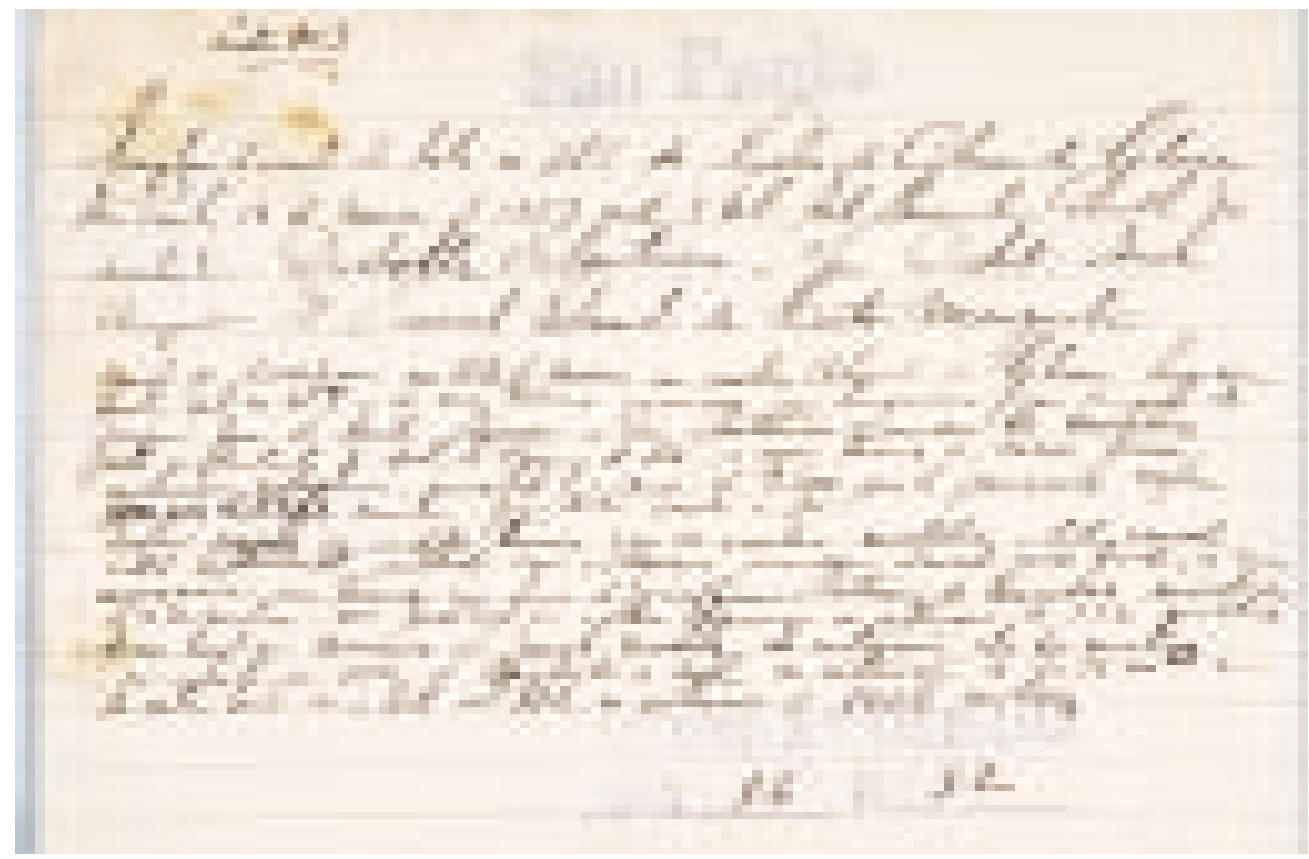

FIGURA 5 - Série Inventários. Ficha manuscrita de Aguirra com resumo da escritura de venda do lote n. 113 do Núcleo da Colônia da Glória. Acervo Museu Paulista da USP. Reprodução de Hélio Nobre. 
Local, data e tabelião

Identificação dos interessados: vendedor e comprador, em letra maior ou em destaque.

Transcrição: resumo dos dados mais relevantes como a descrição da propriedade, valor, confrontantes, limites.

Carimbo: cartório, livro e folhas.

Banco de dados - fichas da área do Cambuci e Glória

Para possibilitar uma articulação do extenso e variável conjunto de informações que caracteriza os fichamentos manuscritos do Arquivo Aguirra - permitindo sua recuperação por ordem cronológica, de assunto e de interessados - organizamos um banco de dados informatizado das fichas que correspondiam à área do Cambuci e Glória, objeto de estudo de nossa dissertação. Analisadas as cerca de 200 fichas, foram criados os seguintes campos de informação para estruturar esse banco:

Acervo: $\quad$ Identifica a coleção do Museu Paulista / Arquivo Aguirra lo banco de dados pode ser ampliado com informações

do mesmo teor, mas de outras fontes documentais).

Tombo: $\quad$ Numeração seqüencial associada ao registro.

Tipo: Identifica o tipo de documento: escritura de venda ou hipoteca, inventário, edital de praça, auto de medição, etc.

Identificação: Nome genérico da propriedade (ś́tio, chácara, terreno, etc.), ou específico, quando houver.

Local: $\quad$ Identifica o bairro, área ou logradouro.

Interessado 1: Identifica o agente da transação imobiliária (vendedor, inventariado, proprietário, etc.)

Interessado 2: Identifica a outra parte da transação imobiliária (comprador, inventariante, penhorado, etc.).

Ano: $\quad$ Ano da transação (1891, p. ex.).

Data: $\quad$ Data precisa do registro documental (13/10/1891, p. ex.).

Descrição: Síntese das principais informações da ficha: dimensão da propriedade, características, confrontantes, etc.

Observação: Síntese de dados complementares: valor da propriedade, referências a outras fichas correlatas, anotações.

Por se tratar de fichas manuscritas, com expressões resumidas e caligrafia de difícil leitura, ocorreram dúvidas na transcrição dos dados para o banco informatizado. Neste caso, a própria possibilidade de aproximação e comparação de dados oriundos de fichas/registros distintos auxiliou na correção ou identificação das informações.

Reproduzimos alguns exemplos de possíveis arranjos desses dados, utilizando um número limitado de registros e parte dos campos que estruturam o banco. 


\section{Exemplo 1}

Neste exemplo foram selecionados todos os negócios imobiliários ocorridos no ano de 1889.

\begin{tabular}{|c|c|c|c|c|c|c|}
\hline Tombo & Tipo & Identificação & Interessado 1 & Interessado 2 & Ano & Data \\
\hline 0098 & $\begin{array}{l}\text { Escritura } \\
\text { de venda }\end{array}$ & $\begin{array}{l}\text { Terras -Chácara } \\
\text { da Glória }\end{array}$ & $\begin{array}{l}\text { Maria Francisca das } \\
\text { Chagas Leal - } \\
\text { vendedora }\end{array}$ & $\begin{array}{l}\text { Emilia Maria da } \\
\text { Anunciação Moraes } \\
\text { - compradora }\end{array}$ & 1889 & $20 / 8 / 1889$ \\
\hline 0028 & $\begin{array}{l}\text { Escritura } \\
\text { de venda }\end{array}$ & $\begin{array}{l}\text { Terreno na } \\
\text { Chácara da } \\
\text { Glória }\end{array}$ & $\begin{array}{l}\text { Maria Francisca das } \\
\text { Chagas Leal - } \\
\text { vendedora }\end{array}$ & $\begin{array}{l}\text { Emilia Maria da } \\
\text { Annunciação Moraes } \\
\text { - compradora }\end{array}$ & 1889 & $20 / 8 / 1889$ \\
\hline 0033 & $\begin{array}{l}\text { Escritura } \\
\text { de venda }\end{array}$ & $\begin{array}{l}\text { Terreno no Núcleo } \\
\text { Colonial da } \\
\text { Glória }\end{array}$ & $\begin{array}{l}\text { Giuseppe Bottechia } \\
\text { e s/m Maria } \\
\text { Bottechia; Luiz } \\
\text { Bottechia e s/m } \\
\text { Thereza Bottechia - } \\
\text { vendedor }\end{array}$ & $\begin{array}{l}\text { Durrupt Henry - } \\
\text { comprador }\end{array}$ & 1889 & $20 / 10 / 1889$ \\
\hline 0035 & $\begin{array}{l}\text { Escritura } \\
\text { de venda }\end{array}$ & $\begin{array}{l}\text { Terreno na Rua } \\
\text { Pólvora }\end{array}$ & $\begin{array}{l}\text { Maria Francisca das } \\
\text { Chagas Leal - viúva } \\
\text { - vendedora }\end{array}$ & $\begin{array}{l}\text { Scuvero Enrico (?) - } \\
\text { comprador }\end{array}$ & 1889 & $24 / 12 / 1889$ \\
\hline 0029 & $\begin{array}{l}\text { Escritura } \\
\text { de venda/ } \\
\text { ratificação }\end{array}$ & $\begin{array}{l}\text { Chácara no Alto } \\
\text { do Cambucy }\end{array}$ & $\begin{array}{l}\text { Joaquim Antonio } \\
\text { Leal - leiloeiro - } \\
\text { vendedor }\end{array}$ & $\begin{array}{l}\text { Guilherme Ellis - } \\
\text { comprador }\end{array}$ & 1889 & $25 / 9 / 1889$ \\
\hline 0034 & $\begin{array}{l}\text { Escritura } \\
\text { de venda }\end{array}$ & $\begin{array}{l}\text { Terreno no } \\
\text { Núcleo da } \\
\text { Glória }\end{array}$ & $\begin{array}{l}\text { Pedro Gaigler es/ } \\
\text { m D (?) Gaigler - } \\
\text { vendedores }\end{array}$ & $\begin{array}{l}\text { Pinoti Aristodemo ou } \\
\text { Aristolino (?) - } \\
\text { comprador }\end{array}$ & 1889 & $26 / 6 / 1889$ \\
\hline
\end{tabular}




\section{Exemplo 2}

Nesta amostragem foram selecionadas todas as transações imobiliárias que envolveram o Banco União, como Interessado 1 (agente, vendedor, etc.) ou como comprador, etc. (Interessado 2).

\begin{tabular}{|c|c|c|c|c|c|c|}
\hline Tombo & Tipo & Identificação & Interessado 1 & Interessado 2 & Ano & Data \\
\hline 0077 & $\begin{array}{l}\text { Escritura de } \\
\text { venda }\end{array}$ & Bairro Lavapés & $\begin{array}{l}\text { Carlos José Botelho, } \\
\text { dr.; e } \mathrm{s} / \mathrm{m} \text { - } \\
\text { vendedores }\end{array}$ & $\begin{array}{l}\text { Banco União de } \\
\text { São Paulo - } \\
\text { comprador }\end{array}$ & 1890 & $20 / 12 / 1890$ \\
\hline 0064 & $\begin{array}{l}\text { Escritura } \\
\text { hipoteca }\end{array}$ & $\begin{array}{l}\text { Terreno na } \\
\text { Chácara da } \\
\text { Glória }\end{array}$ & $\begin{array}{l}\text { João José Maillet e } \\
\text { s/m A (?) Maillet - } \\
\text { devedores }\end{array}$ & $\begin{array}{l}\text { Banco União de } \\
\text { São Paulo - credor }\end{array}$ & 1891 & $19 / 12 / 1891$ \\
\hline 0088 & Adjudicação & $\begin{array}{l}\text { Terrenos - } \\
\text { bairros: Ypiranga } \\
\text { Cambucy e V. } \\
\text { Mariana }\end{array}$ & $\begin{array}{l}\text { Cia. Ypiranga } \\
\text { Tramway e } \\
\text { Construções - } \\
\text { adjudicante }\end{array}$ & $\begin{array}{l}\text { Banco União de } \\
\text { São Paulo - } \\
\text { adjudicado }\end{array}$ & 1893 & $9 / 11 / 1893$ \\
\hline 0095 & Edital de praça & $\begin{array}{l}\text { Lotes - Morro da } \\
\text { Pólvora - } \\
\text { Cambucy }\end{array}$ & $\begin{array}{l}\text { Banco União de } \\
\text { São Paulo - } \\
\text { promovente }\end{array}$ & $\begin{array}{l}\text { Bento José Alves } \\
\text { Pereira, } \\
\text { comendador - } \\
\text { penhorado }\end{array}$ & 1896 & $11 / 7 / 1896$ \\
\hline 0097 & Edital de praça & $\begin{array}{l}\text { Terreno na Vila } \\
\text { Mariana - N. } \\
\text { Colonial Gloria }\end{array}$ & $\begin{array}{l}\text { Banco União de } \\
\text { São Paulo - } \\
\text { promovente }\end{array}$ & $\begin{array}{l}\text { Companhia Paulista } \\
\text { de Materiais - } \\
\text { penhorado }\end{array}$ & 1898 & $16 / 3 / 1898$ \\
\hline 0137 & $\begin{array}{l}\text { Escritura de } \\
\text { venda }\end{array}$ & $\begin{array}{l}\text { Terreno no Morro } \\
\text { da Pólvora - } \\
\text { Cambucy }\end{array}$ & $\begin{array}{l}\text { Banco União de } \\
\text { São Paulo - } \\
\text { vendedor }\end{array}$ & $\begin{array}{l}\text { Mauricio F. Klabin - } \\
\text { comprador }\end{array}$ & 1904 & $29 / 3 / 1904$ \\
\hline 0103 & $\begin{array}{l}\text { Escritura de } \\
\text { venda }\end{array}$ & $\begin{array}{l}\text { Terrenos - } \\
\text { lpiranga, } \\
\text { Cambucy, V. } \\
\text { Mariana e } \\
\text { Glória }\end{array}$ & $\begin{array}{l}\text { Banco União de } \\
\text { São Paulo (Antonio } \\
\text { de Lacerda Franco, } \\
\text { cel. - presidente) - } \\
\text { vendedor }\end{array}$ & $\begin{array}{l}\text { Mauricio F. Klabin - } \\
\text { comprador }\end{array}$ & 1904 & $29 / 3 / 1904$ \\
\hline
\end{tabular}


18. Estes dados, entre outras referências, indicaram o aprofundamento das pesquisas sobre esse proprietário da área da Colônia da Glória.Trata-se de dentista francês, de origem judaica, estabelecido em São Paulo em torno de 1870 , e que foi dono de vários lotes da Colônia, repassando-os em 1890 para as empresas que efetivamente loteariam a área da Vila Deodoro, primeiro investimento urbanizador nessa região. Ver, em especial, capítulos 3.3 e 3.4 (PIRES, 2003) 


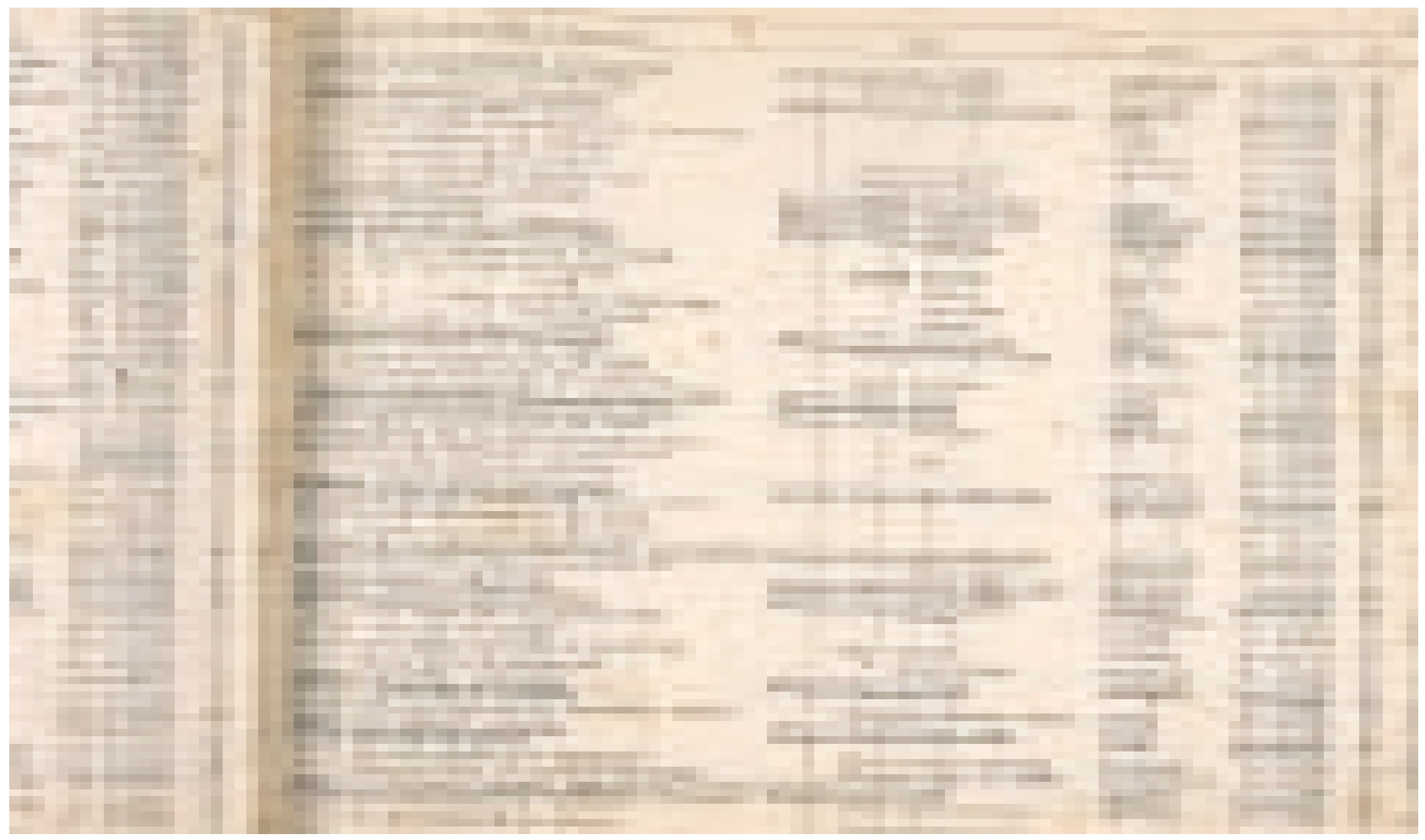

FIGURA 6 - Cadastro de dados organizado por Aguirra a partir dos livros de patentes, provisões e sesmarias. Esses documentos correspondem aos que foram publicados na Revista do IHGSP. Reprodução da folha 5 do índice para os livros 21 a 30 (1778-1802), compilados com o tíiulo Capitania de São Paulo. Patentes, Provisões e Sesmarias concedidas de 1711 a Acervo Museu Paulista da USP. Reprodução de Hélio Nobre. 


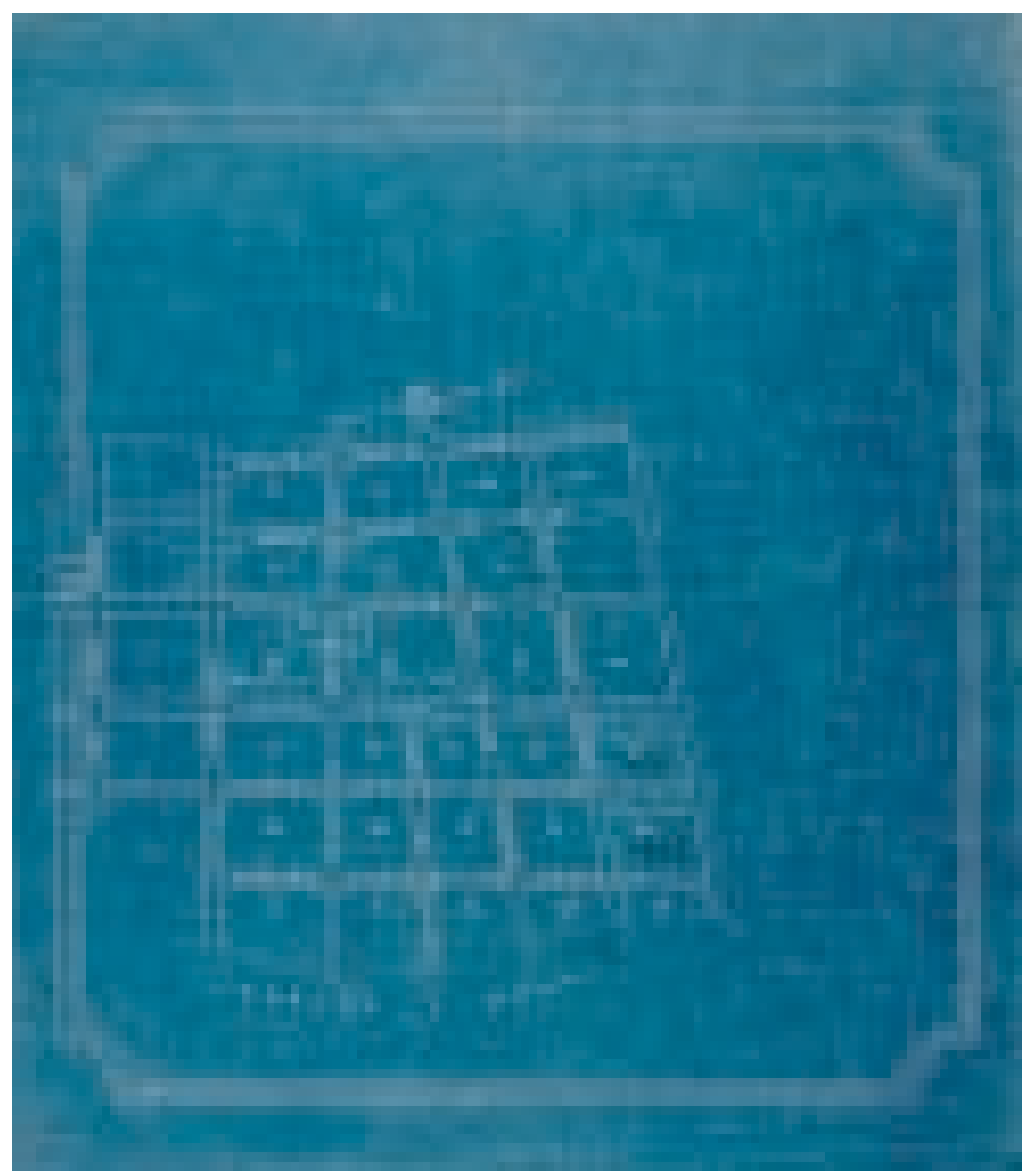

FIGURA 7 - Planta do loteamento de Vila Deodoro, executado na década de 1890 na área da Colônia da Glória. Referência: IC 6052. Acervo Museu Paulista da USP. Reprodução de Hélio Nobre. 


\section{Conclusão}

Para o desenvolvimento da pesquisa documental sobre a área da antiga Colônia da Glória, o conjunto de informações relativas a essa área, existente no Aguirra, foi de fundamental importância. Principalmente pelo fato de já se encontrarem reunidos um conjunto expressivo de registros de negócios ou transferências imobiliárias - tanto por venda ou permuta, como por herança.

A organização desses dados possibilitou a recuperação e a interpretação de uma série de tendências de alteração fundiária e valorização dessas terras, entre outros aspectos. Essas evidências foram comparadas a outros documentos sobre a formação territorial da Glória, complementando e ajustando as conclusões.

Dentre as interpretações que resultaram da análise desse conjunto documental, podemos destacar:

1. Constatação da presença reiterada de alguns proprietários que adquiriram terras nessa área, em momentos distintos. Organizando-se os dados por ordem de interessados, alguns desses nomes se destacam, pela freqüência e importância dos negócios realizados: Samuel Eduardo da Costa Mesquita, Banco União, Maurício F. Klabin, entre outros.

2. O estabelecimento preciso das etapas do processo de concentração e divisão fundiárias que se sucederam nessa área. Confirmaram-se tendências de valorização e definiram-se periodizações mais precisas, associadas a fatos econômicos e sociais contemporâneos a esses negócios imobiliários. Nesse sentido, foram estabelecidas duas etapas para o processo de reorganização fundiária do Núcleo Colonial da Glória, entre 1878 e 1893: um primeiro momento, de 1878 a 1889, caracterizado pela aquisição por investidores privados dos lotes pertencentes aos colonos imigrantes, e uma segunda etapa, entre 1890 e 1893, quando se acelerou a concentração e a aquisição dessas propriedades por empresas e bancos, muitos deles organizados com o Encilhamento, no início da República.

3. Comparação do processo de valorização das terras da Colônia, a partir dos custos declarados nesses documentos, apoiando-se também, neste caso, na documentação cartográfica e descritiva dos fundos documentais sobre as Colônias, existentes em outras fontes, como o Arquivo do Estado e o Arquivo do Poder Judiciário.

Estes poucos exemplos de sistematização de dados, que partiram do próprio conteúdo desse acervo, demonstram as potencialidades de recuperação organizada desse precioso e imenso conjunto de dados que caracteriza o Arquivo Aguirra.

Se João Baptista de Campos Aguirra possuía, ou chegou a organizar, sínteses articuladoras dessa sucessão infindável de propriedades, esse material não integra, infelizmente, até onde se pôde examinar, o acervo que se incorporou ao Museu Paulista.

É necessário, portanto, remontar esse intrincado quebra-cabeça históricoterritorial, cujas peças Aguirra foi metodicamente acumulando em seus agora amarelecidos fichamentos. 


\section{ARTIGOS PUBLICADOS POR JOÃO BAPTISTA DE CAMPOS AGUIRRA}

\section{Revista do Instituto Histórico e Geográfico de São Paulo (IHGSP):}

AGUIRRA,João Baptista de Campos. Relação das sesmarias concedidas na comarca da capital entre os anos de 1559 a 1820. Revista do IHGSP, v. XXV, p. 494-567, 1927, editada em 1928.

Patentes, provisões e sesmarias concedidas nos anos de 1721 a 1742 localizadas nos municípios da capital [...].Revista do IHGSP, v. XXVI, p. 298-451, 1928, editada em 1929.

Patentes, provisões e sesmarias concedidas nos anos de 1721 a 1820 localizadas nos municípios de Parnahyba [...]. Revista do IHGSP, v. XXVII, p. 281-383, 1929, editada em 1930.

Patentes, provisões e sesmarias concedidas nos anos de 1721 a 1820 localizadas nos municípios de São Paulo, Cotia [...]. Revista do IHGSP,v.XXVIII, p. 579-753, 1930, editada em 1931.

Sesmeiros e posseiros. Sesmarias concedidas nos municípios de Jundiahy, Campinas, [...] Revista do IHGSP, v. XXXIV, p.259-339, 1938, editada em 1939.

\section{Revista do Arquivo Histórico Municipal de São Paulo:}

AGUIRRA, João Baptista de Campos.A vida orçamentária de São Paulo durante um século. Revista do Arquivo Histórico Municipal de São Paulo, v. II, p.31-34, jul. 1934.

Estatística. Revista do Arquivo Histórico Municipal de São Paulo,v.VI,VII e VIII, out., nov. e dez. 1934.

.Tombamento de 1817. Propriedades rurais na Capitania de São Paulo. Revista do Arquivo Histórico Municipal de São Paulo, v. X, mar. 1935.

Capitania de São Paulo. Renda provincial do arrendamento de dízimos e passagens de rios durante os três anos de 1738 a 1741. Revista do Arquivo Histórico Municipal de São Paulo,v. XI, p.69-72, abr. 1935.

.Tombamento de 1817. Revista do Arquivo Histórico Municipal de São Paulo, v. XII, p.7780, maio 1935. 


\section{REFERÊNCIAS}

MALHEIRO, Maria Cecília Stávale. O Arquivo Aguirra do Museu Paulista.Anais do Museu Paulista, São Paulo, t. 27, p.201-205, 1977/8.

MELO, Luiz Correia de. Dicionário de autores paulistas. São Paulo: Prefeitura Municipal, 1954.

MENEZES, Raimundo de. Dicionário literário brasileiro. Rio de Janeiro: Livros Técnicos e Científicos, 1978.

MUSEU PAULISTA. Serviço de Documentação Textual e Iconográfica. Guia do Acervo. São Paulo: Museu Paulista, 1994. (ms).

PIRES, Walter. Configuração territorial, urbanização e patrimônio: Colônia da Glória (18761904). 2003. Dissertação (Mestrado em Arquitetura e Urbanismo) - Faculdade de Arquitetura e Urbanismo, Universidade de São Paulo, São Paulo, 2003.

REVISTA DO ARQUIVO MUNICIPAL. São Paulo: Departamento do Patrimônio Histórico, n. 201, 2002. Índice.

Artigo apresentado em 1 1/2003. 
Museu Paulista e trocas intelectuais na escrita da História de Afonso de Taunay

Karina Anhezini

Com o objetivo de compreender a trajetória intelectual de Afonso Taunay pretende-se analisar os intercâmbios estabelecidos entre este historiador e parte de sua rede de sociabilidade reunida em torno da escrita da História de São Paulo no período de 1911 a 1929. Acredita-se que o Museu Paulista assumiu o papel de possibilidade para a escrita da História realizada pelo autor, facilitando a aquisição de obras e documentos, bem como fortalecendo conexões importantes para a concretização de suas obras. A correspondência apresenta-se como principal fonte deste estudo.

PALAVRAS-CHAVE: Intercâmbios.Trajetória intelectual. Correspondência. Museu Paulista. Historiografia. Anais do Museu Paulista. São Paulo. N. Sér.v. 10/11.p.37-60 (2002-2003).

Museu Paulista (Paulista Museum) and intelectual exchanges in the wrintings of Afonso de Taunay's history

Karina Anhezini

Aiming to understand Afonso de Taunay's intellectual trajectory one intends to analyze the exchanges established among this historian and part of his sociability net gathered around the writing of the History of São Paulo in the period from 1911 to 1929. It is believed that Museu Paulista assumed the possibility role for the writing of the History accomplished by the author, facilitating the acquisition of works and documents, as well as strengthening important connections for the materialization of its works. The correspondence comes as the main source for this study.

KEYWORDS: Interchanges. Intellectual trajectory. Correspondence. Museu Paulista. Historiography. Anais do Museu Paulista. São Paulo. N. Sér.v. 10/11.p.37-60 (2002-2003)

Arquivo Aguirra. Fonte Documental sobre a formação territorial de São Paulo

\section{Walter Pires}

artigo trata da importância do Arquivo Aguirra, acervo documental produzido, coletado e organizado por João Baptista de Campos Aguirra (1871-1962), como fonte de informações sobre a formação territorial de São Paulo. Essa coleção, adquirida pelo Museu Paulista em 1962, foi utilizada nas pesquisas que resultaram no texto Configuração territorial, urbanização e patrimônio: Colônia da Glória (1876-1904), dissertação de mestrado para a FAU-USP. A organização dos dados de algumas das séries documentais desse Arquivo, através de um banco de dados informatizado, colaborou na interpretação de tendências de alteração fundiária na área da Glória no final do século XIX, destacando-se: a identificação de proprietários e de negócios imobiliários relevantes; o estabelecimento das etapas de concentração e divisão fundiárias; a valorização dessas propriedades.

PALAVRAS-CHAVE: São Paulo. Coleções. Museu Paulista. Formação territorial urbana.

Anais do Museu Paulista. São Paulo. N. Sér. v. 10/11. p.61-78 (2002-2003).

Aguirra Archives. Documental source about the territorial formation of São Paulo

Walter Pires

The article is about the importance of the Aguirra Archives, a documental collection produced, gathered and organized by João Batista de Campos Aguirra (1871-1962), as a source of information about the territorial formation of São Paulo. This collection, acquired by Museu Paulista in 1962, was used in the researches which resulted in the text Territorial, urbanization and patrimony configuration: Glória's Colony (Colônia da Glória) (1876-1904), master-degree dissertation at FAU-USP. The organization of some of these Archives' series data, through a computerized data bank, helped in the interpretation of the tendencies of land alterations in the area of Glória in the end of the 19th century, with distinction to: the identification of landlords and of relevant estate businesses; the settlement of the concentration and land division phases; the valorisation of these properties. 